\title{
Jared Diamond (2019). Crisis. Cómo reaccionan los países en los momentos decisivos. Barcelona: Debate. Penguin Random House Grupo Editorial, S.A.U. 524 págs. ISBN: 978-84-9992-841-8
}

\author{
Alberto José Pazo Labrador ${ }^{1}$ \\ ${ }^{1}$ Universidad de Vigo. apazo@uvigo.es
}

Recibido: $18 / 03 / 2020$

Aceptado: 14/04/2020

Copyright (C)

Facultad de CC. de la Educación y Deporte. Universidad de Vigo

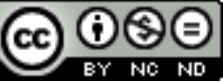

Dirección de contacto:

Alberto José Pazo Labrador

Facultad de Ciencias da Educación e do

Deporte

Campus A Xunqueira, s/n

36005 PONTEVEDRA
Jared Diamond lo ha vuelto a conseguir, ha logrado de nuevo un impacto directo y contundente en el lector que se acerca a su obra buscando conocimiento y aprendizaje. Pero este no es un libro de “educación” sino un libro que "educa”. Decíamos hace algunos años algo similar en este foro, sobre el mismo autor y con motivo de la publicación de su monumental Colapso, que hizo que se tambalearan muchas de nuestras convicciones más sólidas y provocó la reflexión profunda sobre nuestro modo de vida; ocurrió igualmente unos años antes de éste con su recordado Armas, Gérmenes y Acero y años después con el revelador El mundo hasta ayer. ¿Qué podemos aprender de las sociedades tradicionales? donde ponía crudamente, negro sobre blanco, la insensatez de nuestro proceder como especie, al menos en el mundo occidental. En Crisis. Cómo reaccionan los países en los momentos decisivos (titulado originalmente Upheaval. Turnings Points for Nations in Crisis) ya no estamos ante medias tintas sobre nuestro mundo pues lo que se pone de manifiesto es tan inquietante que no podemos escondernos bajo ningún tipo de excusa, ideológica o moral, para no actuar ya ante lo que, según él y caben pocas dudas de que se equivoque, se nos avecina.

Pero el libro ofrece mucho más que una visión prospectiva pues se apoya esencialmente, como buena parte de sus obras, en una mirada retrospectiva buscando conocer, comprender y aprender de aciertos y errores pasados en diversos avatares históricos. El autor parte de una idea sugerente, como es analizar el declive colectivo de los países -en el pasado, en el presente o en un futuro próximo- como si fueran episodios que sufre una persona concreta en su vida: la crisis colectiva se diagnostica y se propone que se trate como una crisis personal, como un "naufragio" individual, aplicando una terapia de choque que debe seguir una serie de pasos descritos minuciosamente y que comienzan por el reconocimiento del problema, sin lo cual no cabe una enmienda adecuada de la trayectoria errónea. Este es el planteamiento que fundamenta en el amplio prólogo, titulado El legado de Coconaut Grove: este curioso título ilustra un episodio luctuoso que afectó a un gran número de víctimas en Boston en los años cuarenta del siglo XX, y que, como se encarga de aclarar en el siguiente capítulo, que constituye la primera parte del libro, propició el surgimiento y el desarrollo de la denominada "terapia de crisis" impulsada por el psiquiatra Erich Lindemann. De manera que los psicólogos especializados en esta terapia identifican hasta doce 
factores que juegan siempre en la probabilidad de resolver las crisis personales, los "naufragios personales" (no en vano, la ilustración de la portada del libro es una significativa evocación de un "naufragio"). Esos doce factores los ejemplifica el autor en su biografía y en las crisis que conoció en su vida personal y profesional, episodios que pudo resolver satisfactoriamente gracias a la identificación y aplicación correcta de buena parte de esos factores. Lo verdaderamente atractivo del libro es cómo el autor adapta estos doce factores establecidos por los terapeutas al desenlace y a la posible resolución de las crisis nacionales.

Reconociendo que lógicamente las analogías entre ambas situaciones -crisis nacionales y crisis personales- distan de ser perfectas, sí que la aplicación de la adaptación de los doce factores del modelo puede resultar válida: es evidente que en los países, como agrupaciones colectivas, juegan un papel destacado las decisiones de las instituciones político-sociales y económicas, hay líderes que pueden tener un peso decisivo en el devenir de los acontecimientos, puede haber partes en conflicto que presenten una difícil reconciliación en los estados posteriores a la resolución, pueden influir factores externos al propio país que condicionen el desenlace... Pero en ambos casos se puede aplicar la definición de crisis que asume el autor: la palabra crisis "deriva del sustantivo griego krisis y del verbo krino, que tienen varios significados vinculados entre sí: separar, decidir, hacer una distinción y también momento decisivo. Por tanto, se podría relacionar la crisis con el momento de la verdad: un punto de inflexión en que la diferencia existente entre las condiciones que se observan antes y después de dicho momento es mucho mayor que la que existe entre la fase anterior y posterior de la mayoría de todos los demás momentos" (p. 17); es ese "punto de inflexión” a que hace referencia el título original, que provoca una "convulsión”.

En la segunda parte del libro, en los sucesivos capítulos, el autor selecciona una serie de países que conoce muy bien por sus vivencias y les aplica un análisis narrativo, verbal y cualitativo, que admite que es parcial y extrapolable de forma incompleta, a expensas de un análisis cuantitativo más riguroso que demuestre las hipótesis y su grado de cumplimiento. En cualquier caso, el método narrativo y comparativo que se aplica aquí a una muestra reducida de países no invalida ni mucho menos unos resultados muy clarificadores, teniendo en cuenta además que es el primer paso de un programa de estudios comparativos más amplio sobre crisis nacionales.

De los doce factores que inciden en el desenlace de las crisis nacionales, y que se explicitan con amplitud en el texto, y que como dijo en alguna entrevista son una suerte de guía práctica para gobernantes en crisis, el autor enfatiza siempre que, además del reconocimiento imprescindible de la existencia de dificultades, del estado de "crisis" - por parte de un individuo o de un país- hay que tener en cuenta actuaciones como construir un "cercado" para acotar aquellos problemas a los que hay que dar solución frente a otros que no deben o no pueden cambiarse; aceptar la responsabilidad propia y evitar la auto-compasión y la culpabilización del prójimo/extranjero mediante una autoevaluación honesta del problema; la propuesta y la aplicación de cambios selectivos tomando como referencia el modelo de países que hayan pasado por trances parecidos en el pasado más o menos lejano; o tener paciencia con los fracasos y los errores y no perder la buena 
disposición para ensayar procedimientos que permitan cambiar lo que no funciona. $\mathrm{Y}$ en ello juegan un papel importante la identidad y el orgullo nacionales -que no todos los países tienen desarrollado en el mismo grado- así como la falta de condicionantes geopolíticos insalvables, como fronteras vulnerables, vecinos poderosos y agresivos, falta de recursos, etc. Y, sobre todo, insiste en que los cambios deben ser selectivos, porque modificar radicalmente una historia de vida nunca es positivo.

¿Cuáles son los siete países que se toman como ejemplos y que, como ya dijimos, el autor conoce muy bien por sus experiencias vitales, que en ocasiones marcaron incluso el devenir de su trayectoria personal y profesional? A todos ellos les aplica la verificación de los doce factores referidos y son países diferentes en tamaño y peso geopolítico, en su desarrollo histórico y en el nivel socioeconómico actual, si bien en su mayor parte pertenecen al primer mundo. A ello se añade la voluntad presente en todo el libro de actuar como una guía explicativa para sus compatriotas estadounidenses, que les permita comprender realidades tan diferentes, lo que enriquece más el análisis si cabe. El capítulo 2 revisa el caso de Finlandia y su exitosa, y a veces incomprendida, manera de aprender a contener y a convivir con la amenaza de su poderoso vecino, la URSS antes, Rusia hoy. La palabra finlandización, de moda hace algunas décadas, expresa mejor que ningún otro término la manera ingeniosa de solventar esa crisis que amenazó, en plena segunda guerra mundial, con acabar con una nación con una fuerte identidad y orgullo nacionales basados en una cultura y una lengua peculiares en Europa, y que hoy es puntera en tecnología, nivel educativo y cultura. En el capítulo 3 se ocupa de los orígenes del Japón moderno, a raíz de una situación de crisis, provocada por amenaza externa e interna, que desembocó en la llamada "era Meiji” en la segunda mitad del XIX, una de las experiencias más fascinantes de superación de un aislamiento secular -sociocultural y geográfico- que se han producido a lo largo de la historia, y que nos asombró a muchos cuando lo estudiamos en el programa lectivo del antiguo COU. Un ejemplo de cómo Japón entra en la historia contemporánea sabiendo aunar la modernización y occidentalización de algunas de sus estructuras -cambio claramente selectivo, tomando como referentes diferentes modelos de diversos países- con el mantenimiento de unas tradiciones seculares intocables.

El capítulo 4 narra el ejemplo del Chile de la época de Allende y la dictadura militar del general Pinochet, un cambio brusco de rumbo, traumático y por lo tanto generador de una situación de crisis nacional. No por menos conocida la historia, por lo cercana que nos queda, el análisis es muy enriquecedor y un ejemplo de superación de una crisis muy grave con la voluntad progresiva de la reconciliación nacional post-dictadura, exitosa - un Chile para todos los chilenos- pero incompleta como se ha visto en los últimos tiempos. Menos conocido es el caso de Indonesia, relatado en el capítulo 5, único de los países analizados correspondientes al mundo menos desarrollado y un tanto "olvidado" por su escaso peso geopolítico. La independencia de los Países Bajos, el papel del "padre fundador” Sukarno y la dictadura de Suharto, la búsqueda de una difícil identidad nacional en un territorio tan fragmentado, la polarización política... son ejemplos de una crisis que evolucionó lentamente, con muchas pérdidas de vidas humanas 
pero que finalmente cuajó en un sentido de la identidad nacional que ha permitido su consolidación como estado.

El capítulo 6 analiza la reconstrucción de Alemania después de la segunda guerra mundial y el largo camino hacia su reunificación, destacando el realismo y el pragmatismo de un líder como Willy Brandt en el reconocimiento de los errores cometidos, en la habilidad de la negociación y la cesión y en la capacidad de superación de enemistades con sus vecinos, creando un marco de confianza internacional, que le ha llevado a liderar el proyecto europeo. Fue sobre todo la reconciliación entre antiguos adversarios dentro de Alemania lo que puso fin a una historia convulsa y el país, con una fuerte identidad y orgullo -sin negar sus culpas y errores- supo aprovechar una crisis para remontar.

El capítulo 7 se ocupa del caso peculiar de Australia, Australia: ¿quiénes somos? Un país que mantiene una fuerte vinculación con Gran Bretaña, cuya independencia ni siquiera fue traumática, que funcionó durante muchos años como una suerte de avanzadilla británica en el Pacífico, manteniendo sus tradiciones, su lealtad a la soberana y su esencia de población anglosajona y blanca mediante las restricciones a la inmigración y el racismo puro y duro. Sin embargo, la transformación gradual de Australia en lo que hoy es, un país desarrollado, rico, con menos vinculación hacia Gran Bretaña y más integración en su marco natural que es la proximidad a Asia, ilustra, no el resultado de una crisis aguda, sino un proceso gradual, acelerado a partir de la segunda guerra mundial "a medida que la identidad británica de Australia degeneraba de realidad a mito” (p. 298), pero donde se rastrean los cambios selectivos, los reconocimientos y las tomas de decisiones que forman parte de los doce factores.

La tercera parte del libro se centra en dos países con crisis en el presente que pueden amenazar su futuro por su desenlace incierto. Por una parte, el autor retorna a Japón y por otra se centra en su país, en EEUU. Japón tiene fortalezas indudables, de todos conocidas, pero también unas debilidades preocupantes: problemas de deuda pública crónicos, la decreciente tasa de natalidad que compromete su renovación generacional ante los recelos frente a la inmigración, el envejecimiento o el papel subordinado de la mujer en la sociedad, que tiene que hacer frente a numerosas barreras sociales. Pero problemas tanto o más inquietantes los plantea su relación con vecinos poderosos como China o Corea, con recelos mutuos derivados de los conflictos pasados y que no han sido solventados por un reconocimiento similar al que llevó a cabo, por ejemplo, Alemania. Y también la falta de recursos, suplida con una presión excesiva e insostenible sobre otros ámbitos del globo. Y por eso, el autor, ve riesgos futuros para Japón. La aplicación de los doce factores al Japón contemporáneo pone de manifiesto estos hechos, pero también la esperanza en superarlos satisfactoriamente a la luz de la experiencia pasada.

Estados Unidos, es sin duda la primera potencia mundial y tiene unas ventajas y fortalezas incomparables que explican su preeminencia. Las ventajas geográficas, geopolíticas y socioeconómicas de EEUU son también conocidas. Pero según el autor, el país corre el riesgo de desperdiciar estas ventajas, pues adolece de una serie de problemas de los cuales el principal es, a su juicio, el acelerado deterioro de la cultura de la negociación y el acuerdo político, base de la democracia, y 
como consecuencia la acentuada polarización de la sociedad en todos los ámbitos. Aquí se explican las peculiaridades del sistema electoral estadounidense, base en gran medida de este deterioro, y aunque la posición del autor sobre el actual inquilino de la Casa Blanca es lo suficiente conocida, su respeto es exquisito, no personificando al causante sino apuntando directamente al sistema y a los “poderes” de la sociedad. La escasa participación electoral y las trabas para un funcionamiento fluido de muchos de los procedimientos en diversos niveles -los políticos estadounidenses van camino de equipararse a los de la antigua Roma: solo acceden al "oficio” los nobles, ricos y poderosos-, acentúan esa sensación de que algo no funciona bien en un sistema político cada vez más claramente dominado por el poder económico. Pero también se constata una profundización de las desigualdades y de la brecha económica entre los estadounidenses, en gran medida consecuencia de la reducción de la inversión en capital humano y en lo público. Todo ello redunda en un declive y en la pérdida de muchas de las ventajas comparativas que hicieron a EEUU grande: "Hay al menos tres tendencias que están contribuyendo a este declive: la cantidad cada vez menor de dinero que invertimos en educación, los resultados cada vez peores que obtenemos a cambio del dinero que invertimos en dicho ámbito y las enormes diferencias que se observan en la calidad de la educación que reciben los estadounidenses” (p. 388). Y también, según el autor, no es menos destacable la prevalencia de un especial “orgullo” diferencial nacional que lleva a desdeñar modelos ajenos exitosos que podrían adoptarse para superar ese declive.

El capítulo 11 es el más “mediático” del libro, el que más ha trascendido, al expresar de forma clara y contundente cuáles son los problemas más graves, las mayores “crisis” del mundo actual y que comprometen el futuro de toda la Humanidad. Para él están muy claros. En primer lugar, la amenaza de las armas nucleares, por conflictos globales (menos probables), regionales, ataques terroristas o accidentes. Asesorado por William Perry, que fue Secretario de Estado de Defensa de EEUU, ilustra los posibles escenarios inquietantes. En segundo lugar, el cambio climático global, cuya cadena causal sintetiza de forma magistral en un diagrama muy expresivo; estamos apreciando día a día sus efectos, desgraciadamente, de tal manera que no podemos pretender ignorarlo consciente o inconscientemente. En tercer lugar, el agotamiento global de los recursos naturales esenciales, por una explotación y un consumo insostenibles. Y, en cuarto lugar, y en relación con el anterior, las desigualdades sociales y económicas globales que se acentúan: "La tasa media per cápita de consumo como el petróleo y los metales, así como la tasa media per cápita de producción de residuos como los plásticos y los gases de efecto invernadero, son unas 32 veces superiores en el primer mundo que en los países en vías de desarrollo” (p. 429). La globalización hace visibles estas desigualdades y también el hecho de que alcanzar el estilo de vida de los países más avanzados en todo el globo es inviable y resultaría catastrófico para nuestro planeta finito.

Un par de apuntes antes de terminar esta reseña. En primer lugar, el autor es geógrafo, aunque su biografía y su formación como fisiólogo y biólogo y sus incursiones bien fundamentadas en la Antropología, en la Historia o en la Ecología lo convierten en un auténtico personaje del Renacimiento. Este libro, como los 
anteriores, es un buen ejemplo de esa síntesis disciplinaria que nos lleva al verdadero conocimiento y comprensión de las cosas. Lean este libro porque refrescarán o reforzarán sus conocimientos geográficos, históricos, económicos, geopolíticos... de una forma amena y adictiva. En segundo lugar, debo destacar precisamente ese papel como geógrafo y la importancia que tiene la Geografía como ciencia de síntesis que queda plasmada claramente en estas páginas. En una época de GPS, globos virtuales y mapas digitales de todo tipo a nuestro alcance, es sorprendente lo ilustrativos y educativos que pueden ser unos sencillos mapas regionales como los que acompañan al texto para contextualizar la ubicación de los países: razón de más para reivindicar el papel del espacio y de la Geografía como ciencia del espacio en un mundo globalizado. Hubo quien, tras "decretarse" el fin de la Historia a raíz de la caída del muro de Berlín, quiso hacer lo mismo y declarar el "fin de la Geografía”: nada más lejos de la realidad, como se puede apreciar en la lectura de las páginas de este apasionante libro.

Escribo estas líneas inmerso en el confinamiento impuesto por el estado de alarma a raíz de la epidemia global del covid-19. Curiosamente, el autor no incluye entre los riegos a futuro el de una pandemia global, quizás porque el libro fue publicado a finales de 2019 y en posteriores entrevistas considera que, en cualquier caso, esta pandemia no constituye una amenaza "existencial” para los seres humanos, que acabe con la vida tal y como la conocemos, como sí puede ocurrir con esos otros cuatro grandes problemas que enuncia. A pesar de todo, el autor es optimista porque considera que la Humanidad cuenta con las herramientas necesarias para paliar y superar crisis globales. Por eso, en tiempos de crisis, de incertidumbre y de desasosiego, nos reconcilia con el ser humano y su capacidad de resiliencia ante las adversidades. 